\title{
Ocotea Aubl. (Lauraceae) no Núcleo Curucutu, Parque Estadual da Serra do Mar, São Paulo, SP, Brasil
}

\author{
Henrique Borges Zamengo de Souza ${ }^{1,2}$ e Paulo Affonso ${ }^{1,2}$
}

Recebido: 6.5.2016; aceito: 17.01.2017

\begin{abstract}
Ocotea Aubl. (Lauraceae) in Núcleo Curucutu, Parque Estadual da Serra do Mar, São Paulo, São Paulo State, Brazil). This paper consists of the taxonomic and floristic survey of the species of Ocotea Aubl. in Núcleo Curucutu, Parque Estadual da Serra do Mar, São Paulo, São Paulo State, Brazil. Identification keys, morphological descriptions, illustrations, geographic distribution, and phenology are presented. The genus is represented in the area by eight species: Ocotea curucutuensis J.B. Baitello, Ocotea dispersa (Nees \& Mart.) Mez, Ocotea laxa (Nees) Mez, Ocotea nutans (Nees) Mez, Ocotea pulchella (Nees \& Mart.) Mez, Ocotea pulchra Vattimo-Gil, Ocotea serrana Coe-Teix, Ocotea venulosa (Nees) Baitello

Keyworks: Atlantic Forest, Cinnamon, Floristic, Taxonomy
\end{abstract}

RESUMO - (Ocotea Aubl. (Lauraceae) no Núcleo Curucutu, Parque Estadual da Serra do Mar, São Paulo, SP, Brasil). Este trabalho consiste no levantamento taxonômico e florístico de Ocotea Aubl. no Núcleo Curucutu, Parque Estadual da Serra do Mar, São Paulo, Estado de São Paulo, Brasil. Chaves de identificação, descrições morfológicas, ilustrações, distribuição geográfica e fenologia são apresentados. O gênero está representado na área por oito espécies: Ocotea curucutuensis J.B. Baitello, Ocotea dispersa (Nees \& Mart) Mez, Ocotea laxa (Nees) Mez, Ocotea nutans (Nees) Mez, Ocotea pulchella (Nees \& Mart) Mez, Ocotea pulchra Vattimo -Gil, Ocotea serrana Coe-Teix, Ocotea venulosa (Nees) Baitello.

Palavras-chave: Canela, Florística, Mata Atlântica, Taxonomia

\section{Introdução}

A família Lauraceae possui uma distribuição pantropical, compreendendo 68 gêneros com 2.978 espécies (The Plant List 2013). Ecologicamente forma um importante grupo na região Neotropical, ocupando a grande maioria dos ecossistemas, do nível do mar a grandes altitudes (Baitello 2016), principalmente nas florestas de terras baixas (Gentry 1988).

No Brasil ocorrem 24 gêneros, com 441 espécies das quais 231 são endêmicas, no Estado de São Paulo estão presentes 13 gêneros com 99 espécies das quais 14 são endêmicas (Quinet et al. 2015).

O maior gênero de Lauraceae é Ocotea, com 428 espécies (The Plant List 2013). Está distribuído na América tropical e subtropical, desde o México até a Argentina, sendo um dos principais representantes da família na Floresta Atlântica (Oliveira-Filho \& Fontes 2000, Santos \& Alves 2012). Presente em todo o território nacional, com 172 espécies das quais 49 estão no estado de São Paulo (Quinet et al. 2015).
O gênero foi descrito por Aublet (1775) tendo como espécie-tipo Ocotea guianensis Aubl. São árvores ou arbustos com flores unissexuadas ou bissexuadas, estames com anteras 4-locelares, locelos arranjados em dois pares sobrepostos, um par de glândulas na base dos filetes dos estames da série III e estaminódios da série IV em geral pouco desenvolvidos (Van der Werff 1991).

Do ponto de vista econômico, encontramos na família, espécies produtoras de madeira de lei, tais como Ocotea porosa Nees (imbuia) e Ocotea odorifera Vell (sassafrás), frutos comestíveis como o de Persea americana Mill (abacateiro), além dos óleos aromáticos e alcalóides usados em cosmetologia, perfumaria e medicamentos (Baitello 2016).

O presente trabalho faz parte do estudo da Flora do Núcleo Curucutu, que a Universidade de Santo Amaro e o Herbário PMSP desenvolvem em parceria. Vários grupos já foram estudados, entre eles podemos citar Ericaceae (Takeuchi \& Affonso

1. Universidade de Santo Amaro, Ciências Biológicas, Rua Prof. Enéas de Siqueira Neto, 340, 04829-300 São Paulo, SP, Brasil

2. Autor para correspondência: zamengo.botanic@gmail.com 
2009), Gentianaceae (Pscheidt \& Affonso 2008), Gesneriaceae (Affonso et al. 2014), Iridaceae (Takeuchi et al. 2008), Orchidaceae com Oncidium Sw. (Rosa \& Affonso 2009) e Melastomataceae com os gêneros Tibouchina Aubl. (Silva \& Affonso 2005), Leandra Raddi (Rodrigues-Lima \& Affonso 2010) e Miconia Ruiz \& Pav. (Rodrigues-Lima \& Affonso 2016).

Com o objetivo de desenvolver o estudo taxonômico das espécies de Ocotea do Núcleo Curucutu, foram realizadas coletas, identificações, descrições e confecção de chave de identificação das espécies, contribuindo assim para o conhecimento da flora local e do Estado de São Paulo.

\section{Material e métodos}

O Núcleo Curucutu, área de estudo deste trabalho, originou-se como Reserva Florestal do Estado, pelo Decreto Estadual n. 36.544/60, a partir da aquisição da Fazenda Curucutu, antiga produtora de carvão (Nogueira, 2001). Atualmente abrange os municípios de Itanhaém, Juquitiba, Mongaguá e São Paulo, situado entre 50 e $870 \mathrm{~m}$ de altitude, com uma área de aproximadamente 37.500 ha (Garcia \& Pirani 2005, SAP 2015).

O Núcleo está inserido em um rebordo granitoxisto-gnaíssico da Serra do Mar. Este arcabouço geológico condiciona a morfologia da região, refletindo na existência de um relevo colinoso, com planícies aluviais e terraços estreitos (Peloggia, 1998). O clima é úmido com alta pluviosidade, e presença de nevoeiros. Na parte mais alta da serra, ocorre a formação chamada "alto-montana", em geral estabelecida sobre solos rasos e/ou orgânicos, em locais sujeitos quase que permanentemente à condensação das massas de ar úmidas procedentes do mar, formando neblina ou até mesmo chuvas fracas durante a maior parte do tempo (Garcia \& Pirani 2005).

Encontra-se no domínio de Mata Atlântica com vegetação campestre e florestal, apresentando as fitofisionomias de campo limpo, campo sujo, capão e mata nebular (Garcia, 2003).

O núcleo é uma das poucas áreas remanescentes de Mata Atlântica do Estado de São Paulo, sendo assim de extrema importância para a preservação e conhecimento das espécies, além de abrigar as nascentes dos rios Capivari e Embu-Guaçu, tributários da Represa Guarapiranga que abastece a região metropolitana de São Paulo, e parte do rio Mambu que abastece a região de Itanhaém (Garcia \& Pirani 2005).

Os espécimes utilizados neste trabalho são provenientes do setor de planalto, com altitudes entre 750 e 850 m, dentro do município de São Paulo. Encontram-se depositados na coleção científica da Universidade de Santo Amaro, e nos Herbários PMSP e SPSF, sendo provenientes de coletas realizadas anteriormente e de junho de 2012 a setembro de 2014, período de desenvolvimento deste trabalho. A herborização seguiu a metodologia usual descrita por Fidalgo \& Bononi (1989).

Para as análises e identificações das amostras foram consultadas literaturas especializadas (Baitello \& Marcovino 2003, Quinet 2005, Brotto et al. 2013), as obras contendo as descrições originais e as coleções de Lauraceae dos herbários PMSP, SPF e SPSF. Os dados de floração e frutificação foram obtidos através dos rótulos das exsicatas, observações de campo e consultas à literatura. As informações sobre a distribuição geográfica de cada espécie foram obtidas através de consultas a literatura da família (Baitello \& Marcovino 2003, Quinet et al. 2015).

A terminologia morfológica empregada é definida em Harris \& Harris (1994) e Gonçalves \& Lorenzi (2011), e algumas terminologias específicas para o grupo, foram extraídas de Baitello (2003). As ilustrações foram confeccionadas a mão livre com o auxílio de um estereomicroscópio e finalizadas pelo ilustrador Klei Rodrigo de Sousa.

\section{Resultados e Discussão}

\section{Ocotea Aubl.}

Arbustos a árvores monoicos e dioicos. Folhas alternas a subverticiladas para o ápice, concolor ou discolor, venação broquidódroma, camptódroma a reticulódroma, raramente 3-plinervada, face adaxial e abaxial com reticulação densa a laxa, domácias pilosas ou escrobiculadas ou ausentes, pecíolo canaliculado a não canaliculado, glabro a piloso. Inflorescência panícula, panícula-tirsóide ou racemo, pedúnculo eventualmente bracteolado, persistentes a caducas. Flores com 6 tépalas; pedicelo glabro a piloso, ocasionalmente bracteolado, persistentes a caducas; hipanto internamente glabro a piloso. Flores masculinas com 9 estames férteis, dispostos em 3 séries de 3, filetes das séries I e II semelhantes entre si, filetes da série III biglandulosos na base, anteras com 4 esporângios sobrepostos ou quase; pistilóide 
ausente, presente ou vestigial. Flores femininas com 9 estaminódios, dispostos em 3 séries de 3; pistilo robusto, estilete conspícuo ou inconspícuo, estigma capitado a trilobado. Fruto bacáceo, parcialmente envolto por uma cúpula de margem simples ou hexalobada.

Chave de identificação para as espécies de Ocotea Aubl. ocorrentes no Núcleo Curucutu

1. Face abaxial do limbo com domácias pilosas ou escrobiculadas

2. Lâminas discolores, domácias escrobiculadas, glabras, pedicelo frutífero de até $2 \mathrm{~mm}$, piloso

2. O. dispersa

2. Lâminas concolores, domácias alvo-pilosas, pedicelo frutífero acima de $2-8 \mathrm{~mm}$, glabro

3. Folha com reticulação laxa na face adaxial, lâminas ovadas, obovadas a elípticas; estames das flores masculinas das séries I e II com anteras triangular-ovaladas 3. O. laxa

3. Folha com reticulação densa na face adaxial, lâminas elípticas; estames das flores masculinas das séries I e II com anteras ovada-retangulares 5. O. pulchella

1. Face abaxial do limbo sem domácias

4. Lâmina discolor

5. Face abaxial do limbo ferrugínea a ocrácea, rufo-lanuginosa, reticulação saliente, laxa; filetes dos estames das séries I, II e III pilosos; fruto com ápice levemente truncado, denso velutino, ferrugíneos, cúpula de margem hexalobada 1. O. curucutuensis

5. Face abaxial do limbo acinzentada, alvo-tomentosa, reticulação subsaliente, densa; filetes dos estames das séries I, II e III glabros; fruto com ápice arredondado, glabro, cúpula de margem simples 6. O. pulchra

4. Lâmina concolor

6. Folhas subverticiladas para o ápice; fruto com cúpula crateriforme

4. O. nutans

6. Folhas alternas ao longo dos ramos; fruto com cúpula trompetiforme ou pateriforme

7. Pecíolo canaliculado, lâminas elípticas de margem inteira não revoluta, ápice longo acuminado, face adaxial glabra; flores masculinas e femininas com pedicelo glabro, pistilóide ausente a vestigial, estipitiforme a filiforme, estigma capitado, trilobado .... 8. O. venulosa

7. Pecíolo não canaliculado, lâminas elípticas a obovadas de margem revoluta, ápice curto acuminado a obtuso, face abaxial glabra a pubescente, tricomas amarelos, pardos a negros; flores masculinas e femininas com pedicelo piloso, pistilóide estipitiforme, estigma capitado

7. O. serrana

Ocotea curucutuensis J.B. Baitello, Acta bot. bras. 15 (3): 445.2001.

Figura $1 \mathrm{a}, \mathrm{b}$

Árvores 5-10 m alt. Folhas com lâmina 5,0-18 × 1,5-7,4 cm, alterna, discolor, coriácea, elíptica a obovada, venação camptódroma, 4-9 pares de nervuras secundárias, margem inteira, ápice agudo, curto acuminado a atenuado, base atenuada, face adaxial brilhante, lâmina jovem pubescente, ferrugíneos a pardos, distribuídos por todo o limbo, lâmina adulta glabrescente a glabra, ferrugíneos a pardos, reticulação laxa, subsaliente, face abaxial opaca, lâmina jovem ferrugínea, denso rufo-lanuginosa, lâmina adulta ferrugínea a ocrácea, rufo-lanuginosa, glabrescente a glabra, reticulação laxa, saliente, domácias ausentes; pecíolo 0,7-2,7 cm compr., não canaliculado, quando em folha jovem piloso, ferrugíneo. Inflorescência panícula- tirsóide, subaxilar, axilar e terminal, pauciflora a multiflora, pedúnculo $0,5-7,5 \mathrm{~cm}$ compr., inteiro, glabrescente a pubescente, lanuginoso, ferrugíneo, não bracteolado. Flores masculinas, tépalas patentes, ovadas, ápice obtuso a arredondado, face externa e interna denso-ferrugíneo-pilosa; pedicelo 1-4 mm, lanoso, tricomas ferrugíneos; hipanto internamente denso-ferrugíneo-piloso; filetes das séries I e II semelhantes entre si, ca. 1/3 a 1/2 do comprimento do estame, estreitos, pilosos a glabrescentes na base, antera não pontuado-glandulosa, eventualmente com esporângios superiores fundidos na primeira série, ovada, ápice retuso a truncado, filetes da série III ca. 1/2 do comprimento do estame, estreitos, pilosos, tricomas ferrugíneos, antera ovada-retangular, ápice truncado, esporângios superiores e inferiores laterais subextrorsos; pistilóide $2,14 \times 0,75 \mathrm{~mm}$, semigloboso, denso piloso, tricomas ferrugíneos, ovário 

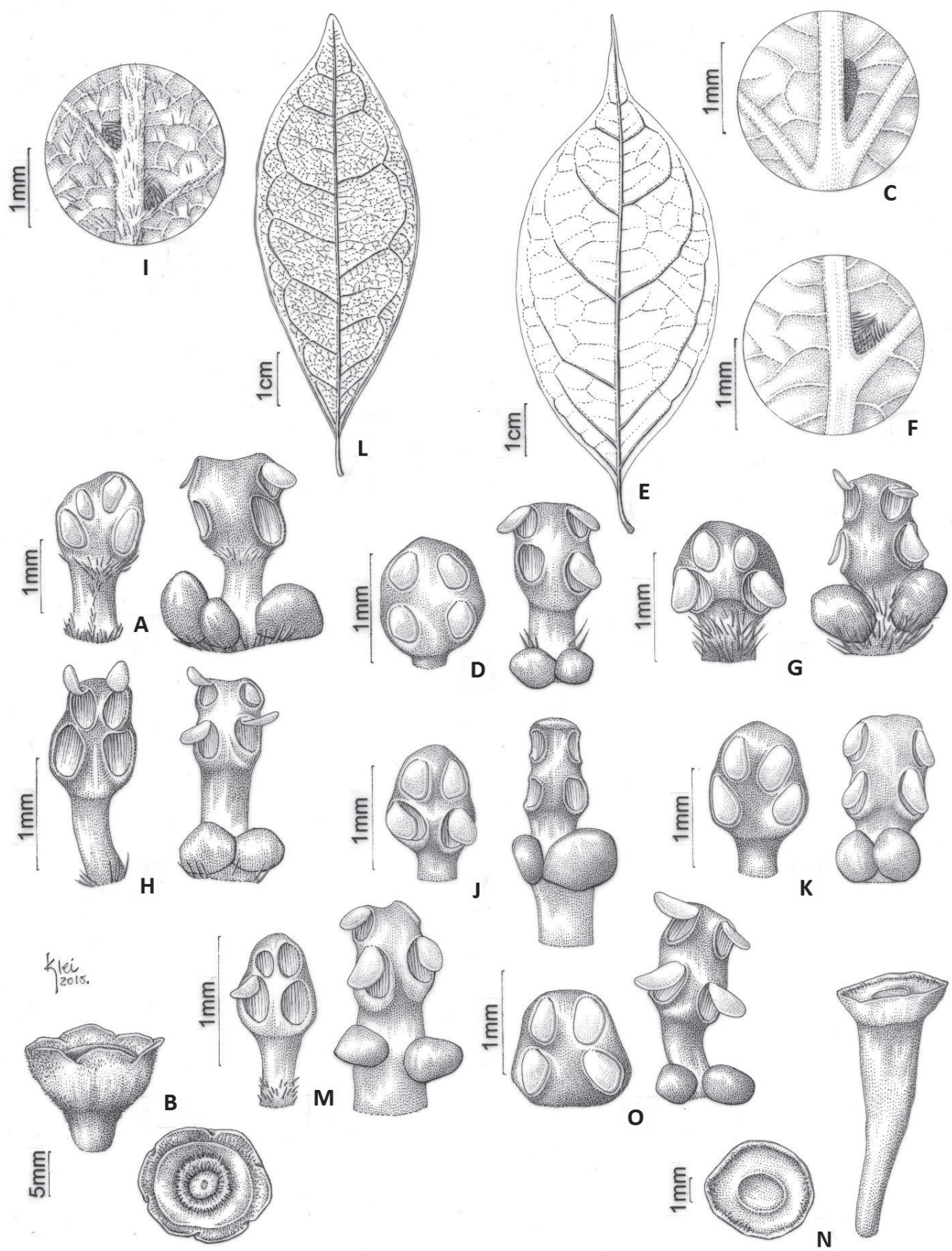

Figura 1. Ocotea curucutuensis. a. Estames das séries 1 e 3. b. Cúpula hexalobada. O. dispersa. c. Domácia escrobiculada glabra. d. Estames das séries 1 e 3. O. laxa. e. Reticulação laxa. f. Domácia pilosa. g. Estames das séries 1 e 3. O. nutans. h. Estames das séries 1 e 3. O. pulchella. i. Domácias pilosas. j. Estames das séries $1 \mathrm{e}$ 3. O. pulchra. k. Estames das séries $1 \mathrm{e}$ 3. O. serrana. 1. Reticulação densa. m. Estames das séries $1 \mathrm{e} 3 . \mathrm{n}$. Vista frontal e súperior da cúpula simples. $O$. venulosa. o. Estames das séries 1 e 3 .

Figure 1. Ocotea curucutuensis. a. Stamen series 1 and 3. b. Hexalobate cupule. O. dispersa. c. Glabrous, scrobiculate domatium. d. Stamen series 1 and 3. O. laxa. e. Lax reticulation. f. Pilose domatium. g. Stamen series 1 and 3. O. nutans. h. Stamen series 1 and 3. O. pulchella. i. Pilose domatium. j. Stamen series 1 and 3. O. pulchra. k. Stamen series 1 and 3. $O$. serrana. 1. Dense reticulation. $\mathrm{m}$. Stamen series 1 and $3 \mathrm{n}$. Front and upper view of simple cupule. O. venulosa. o. Stamen series 1 and 3. 
$1,38 \times 0,75 \mathrm{~mm}$, não atenuado para o estilete, estilete inconspícuo, estigma $0,38 \times 0,63 \mathrm{~mm}$, capitado. Flores femininas, tépalas patentes, ovadas, ápice obtuso a arredondado, face externa e interna denso pilosas, ferrugíneos, pedicelo 1-4 mm, lanoso, ferrugíneo; hipanto internamente denso piloso, ferrugíneo; pistilo $3,52 \times 2,51 \mathrm{~mm}$, ovário $2,76 \times 2,51 \mathrm{~mm}$, semi-globoso, curto-ferrugíneo-tomentoso, estilete inconspícuo, estigma $0,88 \times 0,63 \mathrm{~mm}$, capitado. Fruto 5-20 × 6-20 mm, globoso, ápice levemente truncado, denso-ferrugíneo-velutino, cúpula castanha, glabrescente a pilosa, ferrugíneo, caliciforme a obcônica, margem hexalobada, fauce lisa, tépalas persistentes a caducas, pedicelo 5-16 $\mathrm{mm}$ compr., espesso, pubescente, ferrugíneo.

Material examinado: BRASIL. ItANHAÉm: Trilha do Mirante, 18-III-1999, fl., P. Affonso 366, (UNISA) São Paulo: Trilha do Rio Embu Guaçu, 6-III-1998 fl., $P$. Affonso 108, (UNISA); Trilha do Mirante, 29-X-1999, fr., M.A.S. Mayworm 133, (UNISA); Trilha do Mirante, 20-IV-2001, fl., P. Affonso 1251, (UNISA); Trilha da Mata, 26-VI-2001, fl., fr., M.A.S Mayworm 211, (UNISA); Trilha do Mirante, 17-VIII-2001, fr., P. Affonso 540, (UNISA); Trilha do Mirante, 23-VII-2003, fr., P. Affonso 635, (UNISA); Trilha não especificada, 17-XII-2003, fr., J.B. Baitello 1641, (SPSF); Trilha do Mirante, 28-V-2009, fl., P. Affonso 1141, (UNISA); Trilha do Mirante, 18-VIII-2010, fr., P. Affonso 1235, (UNISA); Trilha do Mirante, 15-V-2010, fl., P. Affonso 1228, (UNISA).

Ocotea curucutuensis é citada como canela do curucutu na coleta J.B. Baitello 1641 (SPSF), é espécie endêmica do Brasil, ocorrendo nos Estados de São Paulo e Rio de Janeiro (Quinet et al. 2015). Em Florestas Ombrófilas, ocorrem principalmente em altitudes entre 800 a $1.600 \mathrm{~m}$, nas Serras do Mar e da Mantiqueira. Em Paraty foi encontrada em baixa altitude ca. $60 \mathrm{~m}$ (Arzolla et al. 2009). Na área de estudo esta espécie é comum nas matas baixas nebulares associadas a campos montanos. Floresce de março a junho e frutifica de junho a agosto com registros para outubro e dezembro.

Essa espécie é afim de Ocotea spixiana (Nees) Mez, deferindo dessa por apresentar a face abaxial do limbo denso rufo-lanuginosa, totalmente encoberta e frutos de 2 a 4 vezes maiores, recobertos por indumento denso-velutino, ferrugíneos, enquanto que Ocotea spixiana apresenta a face abaxial do limbo esparso-tomentosa, ferrugíneos, possibilitando assim a observação da epiderme, frutos de 2 a 4 vezes menores, glabros ou com tricomas restritos ao ápice (Baitello \& Marcovino 2003).

Arzolla et al. (2009) ainda diferenciam $O$. spixiana e $O$. curucutuensis quanto a sua distribuição, a primeira com ocorrência no Distrito Federal, Goiás e Minas Gerais, com nítida preferência por ambientes mais secos, enquanto a segunda ocorre na Floresta Ombrófila Densa Alto-Montana, em ambientes mais úmidos.

No Núcleo Curucutu não se assemelha a nenhuma outra espécie, sendo reconhecida facilmente por sua coloração ferrugínea intensa, tanto em sua lâmina foliar, quanto em seu fruto, facilitando sua observação e identificação em campo.

Ocotea dispersa (Ness) Mez, Jahrb. Königl. Bot. Gart. Berlin 5: 357. 1889.

Figura $1 \mathrm{c}, \mathrm{d}$

Árvores $6 \mathrm{~m}$ alt. Folhas com lâmina 5-10 × 1,7-3,7 cm, alterna, discolor, cartácea, elíptica a obovada, venação broquidódroma, 3-plinervadas na base, 6-7 pares de nervuras secundárias, margem inteira, ápice agudo, acuminado, raro arredondado, base atenuada, cuneada, face adaxial opaca, glabrescente, pubescente, tricomas concentrados ao longo da nervura central, alvos a prateados, reticulação laxa, saliente, face abaxial opaca, rubiginosa ou castanho avermelhado, pilosa, tricomas concentrados ao longo da nervura central a esparsos nas secundárias, alvos a amarelados, reticulação laxa, saliente, domácias escrobiculadas glabras; pecíolo 0,4-1,0 cm compr., não canaliculado, piloso, castanhos. Inflorescência panícula, axilar e terminal, multiflora a pauciflora, pedúnculo 4-12 mm compr., inteiro, piloso, tricomas ferrugíneos, não bracteolado. Flores masculinas, tépalas eretas, ovadas, ápice obtuso, face externa alvo-tomentosa, face interna glabra; pedicelo 1-2 mm compr., denso piloso, tricomas ferrugíneos a alvos; brácteas persistentes 1-3, espatuladas a lanceoladas, dispostas alternadamente ao longo do pedicelo ou na base da flor, denso-alvo-pilosa, caducas a persistentes; hipanto internamente piloso; filetes das séries I e II semelhantes entre si ca. $1 / 4$ a $1 / 3$ do comprimento do estame, estreitos, glabros, antera pontuada, sem fusão de esporângios superiores na primeira série, ovada-retangular, ápice truncado a arredondado, filetes da série III ca. 1/3 a 1/2 do comprimento do estame, largos a estreitos, alvo-pilosos, antera ovada-retangular a retangular, ápice truncado, esporângios superiores laterais, extrorsos, inferiores frontais, subextrorsos; pistilóide 1,26 × 0,38 mm, 
estipitiforme, glabro, ovário $0,75 \times 0,38 \mathrm{~mm}$, atenuado para o estilete, semi-globoso, estilete $0,38 \times 0,20$ $\mathrm{mm}$, glabro, estigma $0,13 \times 0,25 \mathrm{~mm}$, capitado. Flores femininas, tépalas eretas, elípticas, ápice obtuso, face externa e interna glabra; pistilo $1,51 \times$ $0,75 \mathrm{~mm}$, ovário $1,13 \times 0,75 \mathrm{~mm}$, globoso a ovado, glabro, estilete $0,38 \times 0,25 \mathrm{~mm}$, estigma $0,13 \times 0,13$ $\mathrm{mm}$, capitado. Fruto 9-12 × 6-8 mm, semi-globoso, ápice arredondado, glabro, cúpula vermelha, glabra, pateriforme, margem hexalobada pelas tépalas persistentes, interior da fauce lisa, pedicelo $2 \mathrm{~mm}$ compr., espesso, piloso, tricomas alvos a ferrugíneos.

Material examinado: BRASIL. São PAUlo: Trilha do Rio Embu Guaçu, 6-III-1998, fl., P. Affonso 163, (UNISA).

Material adicional examinado: BRASIL. São PAULO: Cananéia, Ilha do Cardoso, 17-VIII-1982, fl., A.C. Maruffa \& $A l$ 21, (SPSF). Parque Estadual da Serra da Cantareira, Núcleo Pedra Grande, 5-IX-2000, fl., Pedro L.R. Moraes 2228 (SPSF). Caraguatatuba, Parque Estadual da Serra do Mar, Núcleo Caraguatatuba, 21-IX-2000, fr., L. Rossi 2175 (SPFS).

Espécie conhecida popularmente como canelinha (Quinet 2005) é endêmica do Brasil e ocorre nos Estados de Espírito Santo, Minas Gerais, Rio de Janeiro, São Paulo, Paraná, Santa Catarina, na Mata Atlântica, em Floresta Ombrófila, Floresta Estacional Semidecidual Submontana e Montana, Floresta Ombrófila Mista Montana (Baitello \& Marcovino 2003, Quinet et al. 2015), além da planície litorânea, e mata ciliar no Parque Estadual da Serra do Mar (Baitello \& Marcovino 2003). Na área de estudo esta espécie é rara, presente em mata nebular. Ocorrem registros de floração para os meses de março, abril, maio, junho, agosto, setembro, outubro e dezembro e de frutificação para os meses de maio, junho, agosto e setembro.

Ocotea dispersa geralmente é confundida com Ocotea divaricata (Nees) Mez, muito provavelmente devido aos seus padrões foliares, alternos, sub-3plinervadas, mas distintas por seu limbo de menor tamanho 5-10 × 1,7-3,7 cm, e face abaxial rubiginosa ou castanho avermelhada, enquanto $O$. divaricata apresenta limbo maior 5-15 × 2-6 cm, domácias em tufos de pelos e face abaxial glabra (Baitello \& Marcovino 2003). No Núcleo Curucutu pode ser diferenciada das outras espécies por seu padrão de venação 3-plinervadas a 5-plinervadas e a coloração da face abaxial rubiginosa ou castanho-avermelhada.
Uma particularidade do exemplar coletado na área de estudo é a ocorrência de domácias glabras, diferentemente do padrão piloso citado por outros autores (Baitello \& Marcovino 2003, Quinet 2005).

Ocotea laxa (Nees) Mez, Jarhrb. Königl. Bot. Gart. Berlin 5: 381. 1889.

Figura $1 \mathrm{e}, \mathrm{f}, \mathrm{g}$

Arvoretas a árvores 2-8 $\mathrm{m}$ alt. Folhas com lâmina 4,8-8 × 2,5-4,1 cm, alterna, concolor, membranácea, ovada a elíptica, venação broquidódroma, 4 a 5 pares de nervuras secundárias, margem inteira, ápice acuminado, base arredondada, obtusa, raro assimétrica, face adaxial opaca, glabra, reticulação laxa, subsaliente, face abaxial brilhante, esparsamente pilosa, tricomas concentrados ao longo da nervura central, alvos, reticulação laxa, saliente, domácias alvo-pilosas; pecíolo 0,5-0,7 cm compr., não canaliculado, glabro. Inflorescência panícula-tirsóide, subterminal a terminal, multiflora, pedúnculo $2-6 \mathrm{~cm}$ compr., inteiro, glabrescente, tricomas alvos a negros, não bracteolada. Flores masculinas, tépalas patentes, ovadas a elípticas, ápice obtuso, face externa glabra, face interna alvo-pilosa; pedicelo 1-5 mm compr., glabrescente, tricomas alvos, não bracteolado; hipanto internamente alvo-piloso; filetes das séries I, II e III semelhantes entre si, ca $1 / 5$ a $1 / 4$ do comprimento do estame, estreitos, alvo-piloso na base, anteras das séries I e II não pontuadas, triangular-ovaladas, ápice arredondado a cuspidado, antera da série III obovalretangular, ápice arredondado a levemente truncado, esporângios superiores frontais, introrsos, inferiores laterais, introrsos; pistilóide $2,89 \times 0,50 \mathrm{~mm}$, estipitiforme, glabro, ovário $1,26 \times 0,50 \mathrm{~mm}$, atenuado para o estilete, semi-globoso, estilete $2,39 \times 0,25 \mathrm{~mm}$, glabro, estigma $0,25 \times 0,38 \mathrm{~mm}$, capitado. Flores femininas tépalas eretas, elípticas, ápice obtuso, face externa glabra, face interna alvo-pilosa; hipanto internamente alvo-piloso; pistilo $2,01 \times 1,88 \mathrm{~mm}$, robusto, ovário $1,51 \times 1,88 \mathrm{~mm}$, globoso, glabro, estilete $0,50 \times 0,38 \mathrm{~mm}$, estigma $0,25 \times 0,50 \mathrm{~mm}$, capitado. Fruto 10-13 × 7-8 mm, elipsóide, ápice levemente truncado, glabro, cúpula vermelha a verde, glabra, trompetiforme, margem hexalobada pelas tépalas persistentes, interior da fauce lisa, pedicelo 6-8 mm compr., espesso, glabro.

Material examinado: BRASIL. ITANHAÉm: Trilha do Campo, 8-VII-1997, fl., R.J.F. Garcia 1211 (UNISA); São Paulo: Trilha do Embú, 22-VIII-1997, fl., fr., $P$. Affonso 117 (UNISA); Trilha do Mirante, 20-IX-1998, 
fl., J.R. Pirani 4440 (PMSP); Trilha sob Pinus, em direção á caixa de água, 28-VII-1999, fl., S.A.P. Godoy 764 (PMSP); Trilha Nova da Mata, 28-IX-2001, fl., fr ., G.M.P. Ferreira 215 (PMSP); Trilha do Mirante, 21-II-2014, fr., H.B.Z. Souza 64 (UNISA); Trilha do Mirante, 21-II-2014, fr., H.B.Z. Souza 65 (UNISA); Trilha do Rio Embú Guaçu 14-VI-2014, fl., fr., H.B.Z. Souza 67 (UNISA); Trilha do Mirante 26-IX-2014, fl., fr., H.B.Z. Souza 69 (UNISA); Trilha do Mirante 26-IX-2014, fl., H.B.Z. Souza 70 (UNISA); Trilha do Mirante, 26-IX-2014, fl., fr., H.B.Z. Souza 72 (UNISA); Trilha do Mirante, 26-IX-2014, fl., H.B.Z. Souza 73 (UNISA).

Conhecida popularmente como canela-fedida, canela-pimenta, canela-preta, canela de folha miúda (Baitello \& Marcovino 2003, Quinet 2005). Espécie endêmica do Brasil, ocorrendo nos Estados de Espírito Santo, Minas Gerais, Rio de Janeiro, São Paulo, Paraná, Santa Catarina, na Mata Atlântica, em Floresta Estacional Semidecidual e Floresta Ombrófila (Baitello \& Marcovino 2003, Quinet et al. 2015). Na área de estudo esta espécie é comum em mata nebular baixa, área reflorestada e campo. Registros de floração foram feitos para os meses de maio, julho, agosto e outubro e de frutificação para julho a agosto. No Núcleo Curucutu floresce de julho, agosto e setembro, e coletado com frutos em março, abril e setembro.

Espécie afim de Ocotea teleiandra (Meisn.) Mez, da qual se difere por apresentar domácias pilosas e tépalas membranáceas, sendo que em $O$. teleiandra não ocorrem domácias (Baitello \& Marcovino 2003). No núcleo Curucutu Ocotea laxa (Nees) Mez e Ocotea pulchella (Nees) Mez apresentam domácias pilosas alvas, nas axilas das nervuras secundárias basais, mas podem ser facilmente diferenciadas pelo formato do limbo ovado a elíptico, reticulação laxa e tépalas persistentes na cúpula em $O$. laxa, enquanto que $O$. pulchella apresenta limbo elíptico, reticulação densa e tépalas caducas.

Ocotea nutans (Nees) Mez, Jahrb. Königl. Bot. Gart Berlin 5: 362. 1889.

Figura $1 \mathrm{~h}$

Arvoretas $3 \mathrm{~m}$ alt. Folhas com lâmina 3-9,1 $\times 1,7-3 \mathrm{~cm}$, alterna, subverticilada para o ápice, concolor, coriácea, elíptica a leve lanceolada-ovalada, venação broquidódroma, 7-8 pares de nervuras secundárias, margem inteira a levemente revoluta, ápice curto a longo acuminado, base aguda, face adaxial opaca, glabra, reticulação densa, saliente, face abaxial opaca, leve rubiginosa quando seca, lâminas jovens com indumento piloso concentrados ao longo da nervura central, tricomas alvos, lâminas adultas glabrescentes com mesmo padrão de indumento e disposição, reticulação densa, saliente, domácias ausentes; pecíolo 0,3-0,4 cm compr., canaliculado, glabro. Inflorescência panícula, axilar, subterminal a terminal, multiflora, pedúnculo $3-4 \mathrm{~cm}$ compr., inteiro, piloso, tricomas castanhos a alvos, não bracteolada. Flores masculinas, tépalas eretas, elípticas a ovaladas, ápice obtuso, face externa, glabra, face interna denso-alvo-pilosa; pedicelo 4-6 mm compr., piloso, tricomas alvos a pardos; hipanto internamente denso-piloso, tricomas alvos; filetes das séries I e II semelhantes entre si, ca $1 / 5$ a 1/3 do comprimento do estame, largos, glabros, antera não pontuado-glandulosa, sem fusão dos esporângios superiores, ovada-retangular, ápice subtruncado a obtuso, filete da série III ca $1 / 2$ do comprimento do estame, estreito, glabro, antera ovalada-retangular, ápice como os das séries anteriores, esporângios superiores laterais e inferiores frontais subextrorsos; pistilóide 2,76 ×0,38 mm, estipitiforme, glabro, ovário $1,51 \times 0,38 \mathrm{~mm}$, atenuado para o estilete, semi-globoso, glabro, estilete $1,01 \times 0,25 \mathrm{~mm}$, glabro, estigma $0,38 \times 0,50 \mathrm{~mm}$, capitado. Flores femininas, tépalas eretas, ovadas, ápice obtuso, face externa glabra, face interna alvo-pilosa, pedicelo piloso, tricomas alvos; hipanto internamente piloso, tricomas alvos; pistilo $1,38 \times 0,75 \mathrm{~mm}$, ovário $0,88 \times 0,75 \mathrm{~mm}$, ovado a leve elíptico, glabro, estilete $0,38 \times 0,38 \mathrm{~mm}$, estigma $0,13 \times 0,13 \mathrm{~mm}$, capitado. Fruto $8-9 \times 6-8 \mathrm{~mm}$, semigloboso, ápice levemente truncado, glabro, cúpula vermelha, glabra, crateriforme, margem hexalobada, interior da fauce lisa, tépalas persistentes a caducas, pedicelo 4-5 mm compr., espesso, glabro.

Material examinado: BRASIL. São PAULo: Trilha do Campo, 22-III-1997, fl., R.J.F. Garcia 1106 (UNISA).

Material adicional: BRASIL. BAHIA: Jacobina, Vale atrás do Hotel Serra do Ouro, Monte Tabor, Beira de Rio, 5-IX-1999, fl., Melo 2923 (SPSF); Paraná: Curitiba, Capão da Imbuia, 20-IX-2009, fr., M.L. Brotto 377 (SPSF); São Paulo: Parque Estadual do Jaraguá, 14-II-2007, fr., F.A.R.D.P Arzolla 1055 (SPSF).

Espécie endêmica do Brasil (Quinet et al. 2015), ocorre nos Estados da Bahia, Espirito Santo, Minas Gerais, São Paulo e Paraná no Cerrado e na Mata Atlântica, nas Florestas Estacional Semidecidual e Ombrófila (Quinet et al. 2015). Na área de estudo esta espécie é rara, encontrada em capão. Foram registradas 
florações entre os meses de fevereiro, março, abril, julho e setembro e frutificação nos meses de janeiro, maio e setembro. No Núcleo Curucutu pode ser diferenciada das demais espécies pela ausência de domácias, face abaxial concolor e por ser a única a apresentar cúpula crateriforme.

Ocotea pulchella (Nees) Mez, Jahrb. Königl. Bot. Gart. Berlin 5: 317. 1889.

Figura 1 i, j

Arvoretas $4 \mathrm{~m}$ alt. Folhas com lâmina 3,5-6,2 × 1,1-2 cm, alterna, concolor, coriácea, elíptica, venação broquidódroma, 4-7 pares de nervuras secundárias, margem inteira a levemente revoluta, ápice agudo a cuspidado, base aguda, face adaxial brilhante, glabra, reticulação densa, subsaliente, face abaxial opaca, leve rubiginosa quando jovem, esparsamente pilosa, dispostos por toda a face, ferrugíneos a castanhos, reticulação laxa, subsaliente, domácias alvo-pilosas; pecíolo 0,4-0,5 cm compr., canaliculado, glabrescente, castanhos. Inflorescência panícula-tirsóide, axilar, subterminal, multiflora, pedúnculo 0,5-1,6 cm compr., inteiro, glabrescente, concentrados próximos às flores, não bracteolada. Flores masculinas, tépalas reflexas, ovaladas, ápice obtuso, face externa alvo-pilosa, próximos às margens, face interna glabra; pedicelo 1-2 mm compr., tomentoso, amarelado a alvo, não bracteolado; hipanto alvo-tomentoso a glabrescente; filetes das séries I e II semelhantes entre sica. 1/3 a 1/2 do comprimento do estame, estreitos, glabros, antera não pontuadoglandulosa, sem fusão dos esporângios superiores, ovada-retangular, ápice obtuso, filetes da série III ca. 1/4 a 1/3 do comprimento do estame, estreitos, glabros, antera retangular, ápice truncado, esporângios superiores laterais, inferiores frontais, subextrorsos; pistilóide $2,14 \times 0,38 \mathrm{~mm}$, estipitiforme, glabro, ovário $0,88 \times 0,38 \mathrm{~mm}$, semi-globoso, atenuado para o estilete, estilete $1,01 \times 0,25 \mathrm{~mm}$, glabro, estigma $0,38 \times 0,50 \mathrm{~mm}$, capitado. Flores femininas, tépalas reflexas, ápice obtuso, face externa e interna pilosa, tricomas alvos, concentrados nas margens, pedicelo alvo-piloso, hipanto internamente piloso, tricomas alvos; pistilo $1,76 \times 0,75 \mathrm{~mm}$, ovário $1,13 \times 0,75 \mathrm{~mm}$, globoso, glabro, estilete $0,63 \times 0,38 \mathrm{~mm}$, estigma $0,13 \times 0,63 \mathrm{~mm}$, capitado. Fruto 5-7 $\times 3-4 \mathrm{~cm}$, ovado a elíptico, ápice mucronado, glabro, cúpula vermelha, glabra, subemisférica a hemisférica, margem simples, interior da fauce lisa, tépalas caducas, pedicelo 2-4 mm compr., delgado, glabro.
Material examinado: BRASIL. SÃo PAULO: Trilha do Campo, 25-VII-1995, fr., S.A.P. Godoy 652 (PMSP); Trilha do Campo, 22-III-1997 fl., R.J.F. Garcia 1115 (UNISA).

Material adicional: BRASIL. SÃo PAULO: Itanhaém, Rio Preto, 11-III-2006, fl., R.J.F. Garcia 2692 (PMSP); Itanhaem, Rio Preto, 11-III-2006, fl., R.J.F. Garcia 2699 (PMSP).

Ocotea pulchella possui muitos nomes populares, como canela-da-folha-dura, canela-do-cerrado, canela-lageana, canelinha, inhumirim (Baitello \& Marcovino 2003). A espécie é encontrada no Brasil, Argentina, Paraguai e Uruguai (Baitello \& Marcovino 2003). No Brasil, possui uma ampla distribuição, abrangendo as regiões Norte (Tocantins), Centrooeste (Distrito Federal, Goiás), Sudeste (Espírito Santo, Minas Gerais, Rio de Janeiro e São Paulo) e Sul (Paraná, Santa Catarina e Rio Grande do Sul), presente no Cerrado, Campo Rupestre e na Mata Atlântica nas Florestas Ciliar Estacional Semidecidual e Ombrófila Densa Montana (Quinet et al. 2015). Na área de estudo esta espécie é rara, encontrada em área de campo próxima a curso de água. Floresce nos meses de fevereiro, março, abril, maio e novembro e frutifica em maio, julho, agosto e setembro.

Ocotea tristis (Nees) Mez, é uma espécie próxima, que apresenta reticulação foliar fortemente laxa na face adaxial (Baitello \& Marcovino 2003).

Ocotea pulchra Vattimo-Gil, Rodriguésia 18-19 (3031): 297. 1956.

Figura $1 \mathrm{k}$

Árvores 6 a 9 m. Folhas com lâmina 4,5-12 × 1,2-3,5 cm, alterna, discolor, coriáceas, obovada, elíptica, venação broquidódroma, 5-8 pares de nervuras secundárias, margem inteira, ápice curto a longo acuminado, base aguda raro assimétrica, face adaxial brilhante, ocrácea, glabrescente, concentrados ao longo da nervura principal, verde, reticulação densa, subsaliente, face abaxial opaca, acinzentada, tomentosa, alvos, dispostos ao longo de toda a lâmina, reticulação densa, subsaliente, domácias ausentes; pecíolo 0,4-1,0 cm compr., canaliculado, glabro. Inflorescência panícula, axilar a terminal, pauciflora, pedúnculo 0,7-1,6 cm compr., inteiro, pubescente, alvos a castanhos, não bracteolada. Flores masculinas, tépalas eretas, ovadas, ápice obtuso, face externa glabra, face interna glabrescente, tomentosa, marginais; pedicelo 3-7 mm compr., glabrescente, pardos, não bracteolado; hipanto internamente 
glabro; filetes das séries I e II semelhantes entre si ca. $1 / 3$ a $1 / 2$ do comprimento do estame, largos, glabros, antera não pontuado-glandulosa, sem fusão de esporângios superiores, ovada-retangular, ápice obtuso a arredondado, filetes da série III ca. 1/3 do comprimento do estame, largos, glabros, antera ovada-retangular, ápice truncado, esporângios superiores e inferiores laterais, extrorsos; pistilóide $2,26 \times 0,63 \mathrm{~mm}$, estipitiforme, alvo-piloso, ovário $0,88 \times 0,63 \mathrm{~mm}$, atenuado para o estilete, semigloboso, piloso, alvo, estilete $1,01 \times 0,38 \mathrm{~mm}$, piloso, estigma $0,38 \times 0,63 \mathrm{~mm}$, capitado. Flores femininas, tépalas eretas, ovadas, ápice obtuso, face externa e interna denso-pilosa, tricomas alvos, pedicelo piloso; hipanto internamente alvo-piloso; pistilo $1,63 \times 1,13 \mathrm{~mm}$, ovário $0,88 \times 1,13 \mathrm{~mm}$, globoso, levemente piloso na base, estilete $0,25 \times 0,38 \mathrm{~mm}$, estigma $0,25 \times 0,50 \mathrm{~mm}$, trilobado, piloso. Fruto 0,6-0,7 $\times 0,6-0,7 \mathrm{~cm}$, globoso, ápice arredondado, glabro, cúpula amarela, glabra, trompetiforme, margem simples, interior da fauce lisa, tépalas caducas, pedicelo 2-3 mm compr., espessado, glabro.

Material examinado: BRASIL. São PAULO: Trilha da Entrada, 3-IV-1998, fl., P. Affonso 258 (UNISA); Trilha da Entrada, 17-IV-1998, fl., Izumisawa 68 (UNISA); Trilha do Mirante, 16-V-1998, fl., Silva 91 (UNISA); Trilha da Entrada, 28-I-1999, fr., Sampaio 154 (UNISA); Trilha da Entrada, 14-VI-2014, fl., H.B.Z.Souza 66 (UNISA).

Material adicional: BRASIL. Rio DE JANEIRO: Nova Friburgo, Reserva Ecológica Municipal de Macaé de Cima, Sítio Sophronites, 31-V-1990, fl., H.C. de Lima 3773 (SPSF); São Paulo: Cunha, Parque Estadual da Serra do Mar, Rio Paraibuna, 31-III-1994, fl., J.B. Baitello 648 (PMSP); Parelheiros, Jd. Novo Parelheiros, Sítio do Sr. José Guilguer Reimberg, 23-VI-1995, fl., fr., S.A.P. Godoy 633 (PMSP); Parelheiros arredores da represa Billings, 15-V-1996, fl., R.J.F. Garcia 870 (PMSP).

Ocotea pulchra conhecida por canela (Baitello \& Marcovino 2003) é endêmica, encontrada nos Estados de São Paulo, Rio de Janeiro e Santa Catarina, em Floresta Ombrófila Densa Montana, Planície Litorânea e Matas Ciliares (Baitello \& Marcovino 2003, Quinet et al. 2015). Na área de estudo esta espécie é pouco frequente, encontrada em campo, borda de mata e em área reflorestada. Floresce de maio a setembro e registros de frutificação foram feitos para os meses de junho e setembro.
Ocotea pulchra possui hábito semelhante à Ocotea bragai Coe-Teixeira, que apresenta flores maiores 8-10 mm diâm. e pecíolo em média mais longo 1-1,5 cm compr. (Baitello \& Marcovino 2003).

A coloração acinzentada da face abaxial da lâmina foliar desta espécie, auxilia sua diferenciação das demais espécies da área de estudo.

Ocotea serrana Coe-Teixeira, Rodriguésia 52: 118. 1980.

Figura $11, \mathrm{~m}, \mathrm{n}$

Arbustos a árvores 1,5-8 m. Folhas com lâmina 1,5-10 × 0,9-4,2 cm, alterna, concolor, subcoriácea, elíptica a obovada, venação broquidódroma a reticulódroma, 4-8 pares de nervuras secundárias, margem revoluta, ápice curto acuminado a obtuso, base atenuada, face adaxial brilhante, pubescente, tricomas concentrados ao longo da nervura central, amarelados, pardos a negros, reticulação densa, saliente, face abaxial opaca, glabra a pubescente, tricomas dispostos por todo o limbo ou concentrados ao longo da nervura central, amarelos, pardos a negros, reticulação densa, saliente, domácias ausentes; pecíolo 0,3-1,0 cm compr., não canaliculado, glabro. Inflorescência racemo a panícula, axilar a terminal, pauciflora, pedúnculo 1-4 mm compr., inteiro, pubescente, tricomas alvos a castanhos, não bracteolada. Flores masculinas, tépalas eretas, elípticas a ovadas, ápice obtuso, face externa glabra, face interna glabra a glabrescente, tricomas alvos; pedicelo 1-7 mm compr., piloso, tricomas alvos a pardos, 1-2 bractéolas alternas a opostas, persistentes, espatuladas a lanceoladas, alvas a pardo-pilosas; hipanto internamente piloso, alvo; filetes das séries I e II semelhantes entre si ca. 1/3 a 1/2 do comprimento do estame, estreito, piloso na base, antera não pontuada, sem fusão dos esporângios superiores, ovada-retangular, ápice arredondado a truncado, filetes da série III ca. 1/3 a 1/2 do comprimento do estame, largos, glabros a pilosos na base, antera ovada-retangular, ápice subtruncado, esporângios superiores laterais, inferiores frontais, extrorsos; pistilóide $2,10 \times 0,68 \mathrm{~mm}$, estipitiforme, glabro, ovário $0,93 \times 0,78 \mathrm{~mm}$, atenuado para o estilete, semi-globoso, glabro, estilete $0,68 \times 0,45 \mathrm{~mm}$, glabro, estigma $0,31 \times 0,38 \mathrm{~mm}$, capitado, glabro; Flores femininas, tépalas eretas, ápice obtuso, face externa e interna alvo-pilosas, esparsos a marginais; pedicelo 1-7 mm compr., piloso, tricomas alvos; pistilo 1,88 $\times 0,63 \mathrm{~mm}$, glabro, ovário $1,26 \times 0,63 \mathrm{~mm}$, globoso, elíptico 
a semi-globoso, glabro, estilete $0,25 \times 0,75 \mathrm{~mm}$, conspícuo, glabro, estigma $0,25 \times 0,25 \mathrm{~mm}$, capitado. Fruto 6-10 × 5-9 mm, globoso, semi-globoso a elíptico, ápice subtruncado, mucronado a arredondado, glabro, cúpula verde a vermelha, glabra, caliciforme a subemisférica, margem simples, interior da fauce com protuberância, tépalas caducas, pedicelo 5-8 mm compr., espessado, glabro.

Material examinado: BRASIL. ItAnHAÉm: Trilha do Mirante, 21-III-1997, fl., R.J.F. Garcia 1090 (UNISA); Trilha do Campo, 15-V-1997, fl., R.J.F. Garcia 1375 (UNISA); São Paulo: Trilha do Campo, 15-XI-1997, fr., Chukr 446 (UNISA); Trilha do Mirante, 13-XII-1997, fr., R.J.F. Garcia 1431 (UNISA); Trilha do Rio Embu Guaçú, 6-III-1998, fl., P. Affonso 151 (UNISA); Trilha do Rio Embu Guaçú, 6-III-1998, fl., P. Affonso 161 (UNISA); Trilha do Mirante, 7-III-1998, fl., P. Affonso 1205 (UNISA); Trilha do Rio Embu Guaçú, 4-IV-1998, fl., P. Affonso 263 (UNISA); Trilha do Rio Embu Guaçú, 4-IV-1998, fl., P. Affonso 267 (UNISA); Trilha do Rio Embu Guaçú, 16-IV-1998, fl., Izumisawa 52 (UNISA); Trilha do Campo, 16-IV-1998, fl., Sampaio 11 (UNISA); Trilha da Entrada, 17-IV-1998, fl., Sampaio 34 (UNISA); Trilha da Entrada, 3-VI-1998, fl., R.J.F. Garcia 1485 (UNISA); Trilha da Entrada, 28-I-1999, fr., P. Affonso 331 (UNISA); Trilha da Entrada, 28-I-1999, fl., Sampaio 153 (UNISA); Trilha do Rio Embu Guaçú, 28-IV-1999, fl., P. Affonso 393 (UNISA); Trilha do Campo, 29-IV-1999, fl., Sampaio 182 (UNISA); Trilha da Mata dos Pinus, 16-III-2001, fl., P. Affonso 506 (UNISA); Trilha do Mirante, 28-V-2009, fl., P. Affonso 1132 (UNISA); Trilha da Entrada, 26-IX-2014, fr., H.B.Z. Souza 68 (UNISA); Trilha do Mirante, 26-IX-2014, fr., H.B.Z. Souza 71 (UNISA); Trilha do Mirante, 26-IX-2014, fr., H.B.Z. Souza 74 (UNISA).

Conhecida popularmente como canelinha (Baitello \& Marcovino 2003) O. serrana é endêmica de São Paulo, restrita a Mata Atlântica em Floresta Ombrófila Densa Montana (Baitello \& Marcovino 2003, Quinet et al. 2015). Esta espécie está sujeita a ameaças, por sua ocorrência restrita, em área próxima a um grande centro urbano, com atividades que degradam seu ambiente (CNCFlora, 2016). Na área de estudo é muito frequente, encontrada em campo, mata baixa nebular, borda de mata e reflorestamento. Floresce entre os meses de janeiro a maio e frutifica de agosto a janeiro.
Espécie próxima de Ocotea paranapiacabensis Coe-Teixeira, da qual se separa pela presença nesta espécie de folhas menores $5-13 \times 2-3 \mathrm{~cm}$, pecíolo mais longos 9-15 mm e inflorescência paniculada, enquanto que em $O$. serrana as folhas possuem 3-9 × 2-4 cm, pecíolo 5-8 $\mathrm{mm}$ e inflorescência racemosa (Baitello \& Marcovino 2003).

Ocotea venulosa (Ness) Baitello, Fl. São Paulo 3: 208. 2003.

Figura 10

Árvore $10 \mathrm{~m}$. Folhas com lâmina 6,8-10 × 2,4-3,9 cm, alterna, concolor, subcoriácea, elíptica, venação broquidódroma, 5-8 pares de nervuras secundárias, margem inteira, ápice longo acuminado, base aguda, face adaxial opaca, glabra, reticulação laxa, subsaliente, face abaxial opaca, glabra, reticulação laxa, saliente, domácias ausentes; pecíolo 0,9-1,2 cm compr., canaliculado, glabro. Inflorescência panícula tirsóide, axilar, multiflora, pedúnculo 1,8-2,9 cm compr., estriado, glabro, não bracteolada. Flores masculinas, tépalas eretas, estreito-ovadas, ápice subobtuso, face externa e interna glabra; pedicelo 1-3 mm, não bracteolado, glabro; hipanto internamente glabro; filetes dos estames das séries I e II semelhantes entre si ca. 1/4 a 1/3 do estame, estreitos, esparso-pilosos, antera não pontuada, sem fusão dos esporângios superiores, ovada-retangular, ápice obtuso a arredondado, filetes dos estames da série III ca. 1/5 do comprimento do estame a inconspícuo, glabros, anteras ovadoretangulares, ápice subtruncado a arredondado, esporângios superiores e inferiores laterais; pistilóide $0,88 \times 0,25 \mathrm{~mm}$, ausente a estipitiforme ou filiforme, glabro, ovário $0,63 \times 0,25 \mathrm{~mm}$, atenuado para o estilete, semi-globoso, glabro, estilete $0,38 \times 0,13 \mathrm{~mm}$, estigma $0,25 \times 0,13 \mathrm{~mm}$, capitado. Flores femininas tépalas eretas, ovadas, ápice obtuso, face externa e interna glabra; pedicelo glabro; hipanto internamente glabro; pistilo $1,51 \times 0,88 \mathrm{~mm}$, glabro, ovário $0,75 \times 0,88 \mathrm{~mm}$, semi-globoso a globoso, glabro, estilete inconspícuo, estigma $0,25 \times 0,25 \mathrm{~mm}$, capitado, trilobado, glabro. Fruto 10-12 × 7-9 mm, elipsóide, ápice truncado, glabro, cúpula verde, glabra, subemisférica, margem simples, fauce lisa, tépalas caducas, pedicelo 2-4 mm espessado, glabro.

Material examinado: BRASIL. São PAUlo: Trilha do Rio Embu Guaçú, 26-II-1999, fl., Izumisawa 178 (UNISA); Trilha do Rio Embu Guaçú, 14-II-2002, fl., R.J.F. Garcia 2131 (PMSP); Trilha do Rio Embú Guaçu, 11-XII-2002, fl., R.A. Alves 48 (PMSP). 
Material adicional: BRASIL. SÃo PAULO: São Paulo, Parelheiros, Camping Ana Paula, 22-VI-1995, fl., fr., S.A.P. Godoy 597 (PMSP); São Paulo, Represa da Guarapiranga, 18-XI-2002, D. Barbieri, s/n (PMSP 7226).

Espécie endêmica dos Estados de São Paulo e Rio de Janeiro, restrita ao bioma Mata Atlântica em Floresta Ombrófila Densa Montana (Baitello \& Marcovino 2003, Quinet et al. 2015). Na área de estudo esta espécie é rara, encontrada em mata. Registros de floração foram feitos para os meses de novembro, dezembro e de fevereiro a maio e frutificação para abril.

Ocotea teleiandra (Meisn.) Mez assemelha-se a $O$. venulosa diferindo desta por apresentar um menor número de nervuras laterais na lâmina foliar, 2-4 pares, e sua reticulação é menos densa (Baitello \& Marcovino 2003). No Núcleo Curucutu $O$. venulosa se assemelha a $O$. dispersa e $O$. laxa, diferindo-se de ambas por apresentar pecíolo canaliculado e ausência de domácias. Também pode se diferenciar de todas as demais espécies presentes na área de estudo, por ser a única com ambas as faces da lâmina glabra, e por apresentar estigma trilobado nas flores femininas.

\section{Agradecimentos}

A equipe do Núcleo Curucutu pelo apoio nas coletas. Ao Instituto Florestal pela autorização para a realização deste trabalho. Aos curadores dos herbários visitados, Ricardo José Francischetti Garcia (PMSP), João Batista Baitello (SPSF) e Renato de Mello-Silva (SPF). A João Batista Baitello e Eduardo Hortal Pereira Barretto, pelas sugestões e críticas. À Universidade de Santo Amaro pelo apoio.

\section{Literatura citada}

Affonso, P., Takeuchi, C. \& Nakano, R.K. 2014. Levantamento de Gesneriaceae Rich. \& Juss. no Núcleo Curucutu, Parque Estadual da Serra do Mar, São Paulo, SP, Brasil. Revista Hoehnea 41: 563-572.

Arzolla, F.A.R.D.P., Baitello, J.B., Shepherd, G.J., Paula, G.C.R. \& Bertoncello, R. 2009. Uma revisão da distribuição de Ocotea curucutuensis J.B. Baitello na região sudeste do Brasil. Biota Neotropica 9: 21-25.

Baitello, J.B. \& Marcovino, J.R. 2003. Ocotea Aubl. In: M.G.L. Wanderley, G.L. Shepherd, T.S. Melhem, A.M. Giulietti, M. Kirizawa (eds.). Flora Fanerogâmica do Estado de São Paulo. RiMa, São Carlos, v. 3, pp. 179-208.
Baitello, J.B. 2016. A importância das Lauraceae na Mata Atlântica Brasileira. Disponível em http://www. ambiente.sp.gov.br/pesquisaambiental/pesquisas/aimportancia-das-lauraceae-na-mata-atlantica-brasileira/ (acesso em 18-III-2016).

Brotto, M.L, Cervi,A.C.\& Santos, E.P. 2013. O gênero Ocotea (Lauraceae) no Estado do Paraná, Brasil. Rodriguésia 64:495-525.

CNCFlora. 2016. Ocotea serrana. In: Lista Vermelha da flora brasileira versão 2016. Centro Nacional de Conservação da Flora. Disponível em http://cncflora. jbrj.gov.br/portal/pt-br/profile/Ocotea serrana (acesso em 15-IX-2016).

Fidalgo, O. \& Bononi, V.L.R. 1989. Técnicas de coleta, preservação e herborização de material botânico. São Paulo: Instituto de Botânica.

Garcia, R.J.F. 2003. Estudo Florístico dos campos altomontanos e matas nebulares do Parque Estadual da Serra do Mar - Núcleo Curucutu, São Paulo, SP, Brasil. Tese de Doutorado, Universidade de São Paulo, São Paulo.

Garcia, R.J.F \& Pirani, J.R. 2005. Análise Florística, Ecológica e Fitogeográfica do Núcleo Curucutu, Parque Estadual da Serra do Mar, São Paulo-SP, com ênfase nos campos junto à crista da Serra do Mar. Revista Hoehnea 32: 1-48.

Gentry, A. 1988. Changes in plant community diversity and floristic composition on environmental and geographical gradients. Annals of the Missouri Botanical Garden 69: 557-593.

Gonçalves, E.G. \& Lorenzi, H. 2011. Morfologia Vegetal Organografia e Dicionário Ilustrado de Morfologia das Plantas Vasculares, 2 ed. São Paulo. Instituto Plantarum, Nova Odessa.

Harris, J.G. \& Harris, M.W. 1994. Plant identification terminology: an illustrated glossary. Spring Lake Publishing, Utah.

Nogueira, S.M.B. 2001. Análise da suscetibilidade ambiental e diretrizes para o zoneamento do Núcleo Curucutu do Parque Estadual da Serra do Mar (SP). Dissertação de Mestrado, Universidade Estadual Paulista, Rio Claro.

Oliveira Filho, A.T. \& Fontes, M.A.L. 2000. Patterns of floristic differentiation among Atlantic forests in Southeastern Brazil and the influence of climate. Biotropica 32: 793-810.

Peloggia, A. 1998. O Homem e o Ambiente Geológico Geologia, sociedade e ocupação urbana no Município de São Paulo. Editora Xamã. São Paulo.

Pscheidt, A.C. \& Affonso, P. 2008. Levantamento de Gentianaceae Juss. no Núcleo Curucutu, Parque Estadual da Serra do Mar, São Paulo. Revista do Instituto Florestal 20: 147-153.

Quinet, A. 2005. Lauraceae na reserva biológica de poço das antas, Silva Jardim, Rio de Janeiro, Brasil. Acta Botanica Brasilica 19: 563-572. 
Quinet, A., Baitello, J.B., Moraes, P.L.R., Assis, L., Alves, F.M. 2015. Lauraceae. In: Lista de Espécies da Flora do Brasil. Jardim Botânico do Rio de Janeiro. Disponível em http://floradobrasil.jbrj.gov.br/jabot/floradobrasil/ FB143 (acesso em 09-IV-2016).

Rodrigues-Lima, A.A. \& Affonso, P. 2010. Levantamento de Leandra Raddi no Núcleo Curucutu, Parque Estadual da Serra do Mar, São Paulo. Revista do Instituto Florestal 22: 15-32.

Rodrigues-Lima, A.A \& Affonso, P. 2016. Miconia Ruiz \& Pav. no Núcleo Curucutu, Parque Estadual da Serra do Mar, Estado de São Paulo, Brasil. Revista Hoehnea 43: 77-86.

Rosa, D.A. \& Affonso, P. 2009. Levantamento do gênero Oncidium Sw. sensu lato (Orchidaceae) no Núcleo Curucutu, Parque Estadual da Serra do Mar, São Paulo. Revista do Instituto Florestal 21: 55-62.

Santos, S.O. \& Alves, M. 2012. Flora da Usina São José, Igarassu, Pernambuco: Lauraceae. Revista Rodriguésia 63: 689-703.

Silva, C.V. \& Affonso, P. 2005. Levantamento de Tibouchina Aubl. (Melastomataceae) no Parque Estadual da Serra do Mar, Núcleo Curucutu, São Paulo. Revista do Instituto Florestal 17: 195-206.
Sistema Ambiental Paulista - S.A.P. 2015. Parque Estadual da Serra do Mar - Núcleo Curucutu. Disponível em http://www.ambiente.sp.gov.br/parque-serra-domar-nucleo-curucutu/ (acesso em: 02-III-2015).

Souza, V.C. \& Lorenzi, H. 2012. Botânica Sistemática: guia ilustrado para identificação das famílias de Fanerógamas nativas e exóticas no Brasil, baseado em APG III. 3 ed. Instituto Plantarum, Nova Odessa.

Takeuchi, C. \& Affonso, P. 2009. Levantamento de Ericaceae Juss. no Núcleo Curucutu, Parque Estadual da Serra do Mar, São Paulo. Revista do Instituto Florestal 21: 131-138.

Takeuchi, C., Affonso, P. \& Chukr, N.S. 2008. Levantamento de Iridaceae Juss. no Núcleo Curucutu, Parque Estadual da Serra do Mar, São Paulo. Revista do Instituto Florestal 20: 51-63.

The Plant List. 2013. Disponível em http://www. theplantlist.org/1.1/browse/A/Lauraceae/ (acesso em 09-IV-2016).

Van der Werff, H. 1991. A key to the genera of Lauraceae in the new world. Annals of the Missouri Botanical Garden 78: 377-387. 